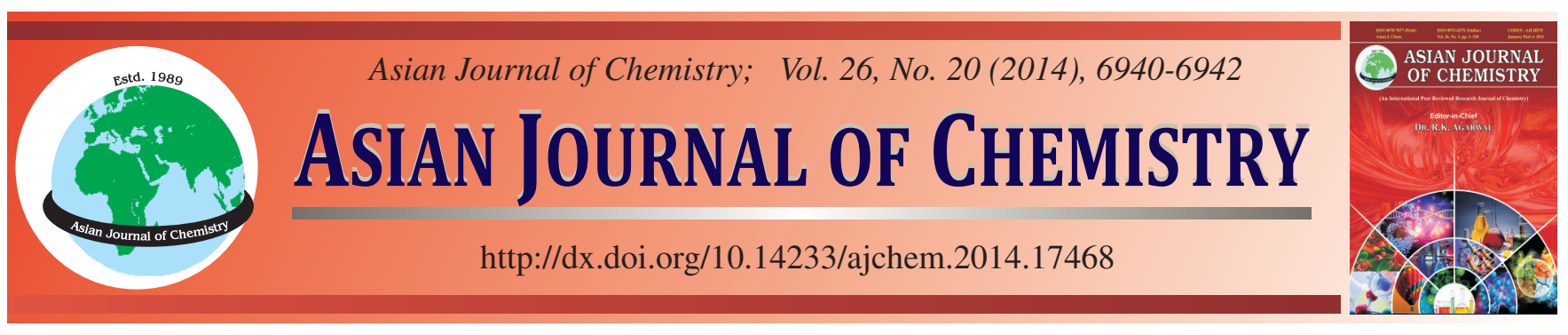

\title{
Synthesis and Characterization of Methoxy-Substituted Salamo-Type Bisoximes Based on Bis(aminooxy)alkane and 3-Methoxy-2-hydroxybenzaldehyde
}

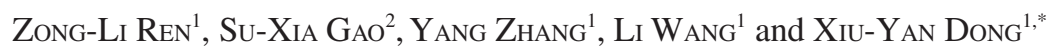

${ }^{1}$ School of Chemical and Biological Engineering, Lanzhou Jiaotong University, Lanzhou 730070, P.R. China

${ }^{2}$ School of Environmental and Municipal Engineering, Lanzhou Jiaotong University, Lanzhou 730070, P.R. China

*Corresponding author: E-mail: dxy568@163.com

Received: 25 February 2014;

Accepted: 5 May 2014;

Published online: 25 September 2014;

AJC-16044

Four new methoxy-substituted Salamo-type bisoxime compounds 6,6'-dimethoxy-2,2'-[(propylene-1,3-diyldioxy)bis(nitrilomethylidyne)]diphenol $\left(\mathbf{H}_{2} \mathbf{L}^{\mathbf{1}}\right), 6,6$ '-dimethoxy-2,2'-[(butylene-1,4-diyldioxy)bis(nitrilomethylidyne)]diphenol $\left(\mathbf{H}_{2} \mathbf{L}^{2}\right), 6,6$ '-dimethoxy2,2'-[(propane-1,5-diyldioxy)bis(nitrilome-thylidyne)]diphenol $\left(\mathbf{H}_{2} \mathbf{L}^{3}\right)$ and 6,6'-dimethoxy-2,2'-[(hexane-1,6-diyldioxy)bis(nitrilomethylidyne)]diphenol $\left(\mathbf{H}_{2} \mathbf{L}^{4}\right)$ have been synthesized through condensation reactions under hot ethanol medium, respectively and characterized by elemental analyses, IR, UV-visible and ${ }^{1} \mathrm{H}$ NMR spectra.

Keywords: Synthesis, Salamo-type bisoxime compound, Characterization.

\section{INTRODUCTION}

Salen-type compounds are a kind of linear tetradentate, $\mathrm{N}_{2} \mathrm{O}_{2}$-coordinating ligands which are obtained by condensation reaction of ketones or aldehydes with diamine. They are used extensively in the catalysis activity, biological systems, sterilization and antivirus in the last century ${ }^{1-5}$. Recently, a prefreable class of Salen-type bisoxime ligands was reported, using an $O$-alkyloxime unit [-CH=N-O- $\left.\left(\mathrm{CH}_{2}\right)_{\mathrm{n}}-\mathrm{O}-\mathrm{N}=\mathrm{CH}-\right]$ instead of the $\left[-\mathrm{CH}=\mathrm{N}-\left(\mathrm{CH}_{2}\right)_{\mathrm{n}}-\mathrm{N}=\mathrm{CH}-\right]$ group. The large electronegativity of oxygen atoms is expected to affect strongly the electronic properties of the $\mathrm{N}_{2} \mathrm{O}_{2}$ coordination sphere, which can lead to different and novel properties and structures of the resulting complexes $^{6-9}$. The new Salen-type compounds and their complexes play an important role in the development of coordinating chemistry ${ }^{10-12}$. In this article, we report the synthesis of four new Salen-type bisoxime compounds from 3-methoxy-2hydroxy-benzaldehyde and several bis(aminooxy)alkane with different long-chain alkane molecules, 6,6'-dimethoxy-2,2'[(propylene-1,3-diyldioxy)bis(nitrilomethylidyne)]diphenol $\left(\mathbf{H}_{2} \mathbf{L}^{\mathbf{1}}\right)$, 6,6'-dimethoxy-2,2'-[(butylene-1,4-diyldioxy) bis(nitrilo-methylidyne)]diphenol $\left(\mathbf{H}_{2} \mathbf{L}^{2}\right), 6,6$ '-dimethoxy-2,2'[(propane-1,5-diyldioxy)bis(nitrilome-thylidyne)]diphenol $\left(\mathbf{H}_{2} \mathbf{L}^{3}\right)$ and 6,6'-dimethoxy-2,2'-[(hexane-1,6-diyldioxy)bis(nitrilo-methylidyne)]diphenol $\left(\mathbf{H}_{2} \mathbf{L}^{4}\right)$ and their characterizations.

\section{EXPERIMENTAL}

3-Methoxy-2-hydroxy-benzaldehyde ( $\geq 98 \%)$, 1,3-dibromopropane, 1,4-dibromobutane, 1,5-dibromopentane and 1,6-dibromohexane were purchased from Alfa Aesar and used without further purification. The other reagents and solvents were analytical grade reagents from Tianjin Chemical Reagent Factory. The physico-chemical measurements are the same as previous literature $^{13}$.

Synthetic route to Salamo-type bisoxime compounds $\mathbf{H}_{2} \mathbf{L}^{1}-\mathbf{H}_{2} \mathbf{L}^{4}$ are shown in Fig. 1.

1,3-bis(Aminooxy)propane, 1,4-bis(aminooxy)butane, 1,5-bis(aminooxy)pentane and 1,6-bis(aminooxy)hexane were synthesized according to an analogous method reported earlier ${ }^{13}$.

Preparation of 6,6'-dimethoxy-2,2'-[(propylene-1,3diyldioxy)bis(nitrilomethylidyne)]diphenol $\left(\mathbf{H}_{2} \mathbf{L}^{1}\right)$ : To an ethanolic solution $(5 \mathrm{~mL})$ of 3-methoxy-2-hydroxy-benzaldehyde (608.6 mg, $4 \mathrm{mmol}$ ) was added an ethanolic solution (5 mL) of 1,3-bis(aminooxy)propane (212.2 mg, $2 \mathrm{mmol}$ ). After the solution had been stirred at $55^{\circ} \mathrm{C}$ for $3 \mathrm{~h}$, then cooled to room temperature. The formed white precipitate was separated by filtration and washed successively with ethanol and ether. The product was dried under vacuum to yield the compound $\mathbf{H}_{2} \mathbf{L}^{1}$, Yield, $87.7 \%$, m.p. 437-438 K.

Preparation of 6,6'-dimethoxy-2,2'-[(butylene-1,4diyldioxy)bis(nitrilomethylidyne)]diphenol $\left(\mathbf{H}_{2} \mathbf{L}^{2}\right)$ : To an ethanolic solution $(5 \mathrm{~mL})$ of 3-methoxy-2-hydroxybenzaldehyde (608.6 mg, $4 \mathrm{mmol}$ ) was added an ethanolic solution (5 mL) of 1,4-bis(aminooxy)butane ( $240.3 \mathrm{mg}, 2 \mathrm{mmol}$ ). After the solution had been stirred at $55^{\circ} \mathrm{C}$ for $3 \mathrm{~h}$, then cooled to room temperature. The formed white precipitate was separated by filtration and washed successively with ethanol and ether. 


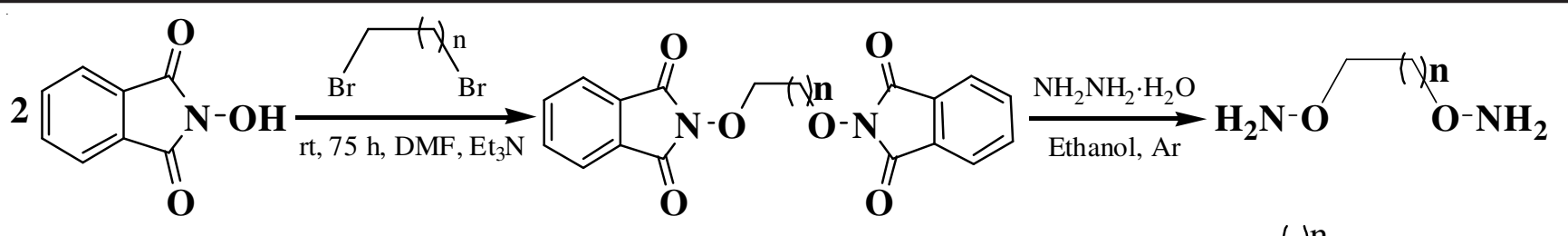<smiles>COc1cccc(C=O)c1O</smiles>

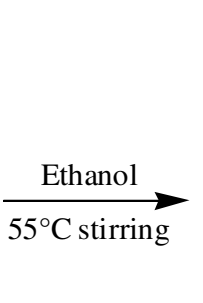<smiles>COc1cccc(/C=N/OC[Al]O/N=C/c2cccc(OC)c2O)c1O</smiles>

Fig. 1. Synthetic route to Salamo-type bisoxime compounds $\mathrm{H}_{2} \mathrm{~L}^{1}-\mathrm{H}_{2} \mathrm{~L}^{4}(\mathrm{n}=2-5)$

The product was dried under vacuum to yield the compound $\mathbf{H}_{2} \mathbf{L}^{2}$, Yield, $68.8 \%$, m.p. 387-388 K.

Preparation of 6,6'-dimethoxy-2,2'-[(propane-1,5diyldioxy)bis(nitrilome-thylidyne)]diphenol $\left(\mathbf{H}_{2} \mathbf{L}^{3}\right)$ : To a ethanolic solution ( $5 \mathrm{~mL}$ ) of 3-methoxy-2-hydroxybenzaldehyde (152.2 $\mathrm{mg}, 1 \mathrm{mmol})$ was added an ethanolic solution $(2 \mathrm{~mL})$ of 1,5-bis(aminooxy)pentane $(67.1 \mathrm{mg}, 0.50 \mathrm{mmol})$. After the solution had been stirred at $55^{\circ} \mathrm{C}$ for $4 \mathrm{~h}$, then cooled to room temperature. The light yellow precipitate was filtered and washed successively with a mixture of ethanol and $n$-hexane ( $\mathrm{v}: \mathrm{v}=1: 4)$ and $n$-hexane, respectively. The product was dried under vacuum to yield the compound $\mathbf{H}_{2} \mathbf{L}^{3}$, Yield, $63.2 \%$, m.p. 372-373 K.

Preparation of 6,6'-dimethoxy-2,2'-[(hexane-1,6diyldioxy)bis(nitrilomethylidyne)]diphenol $\left(\mathbf{H}_{2} \mathbf{L}^{4}\right)$ : To a hot ethanolic solution $(5 \mathrm{~mL})$ of 3-methoxy-2-hydroxybenzaldehyde (152.2 mg, $1 \mathrm{mmol}$ ) was added an ethanolic solution (2 mL) of 1,6-bis(aminooxy)hexane (74.1 mg, $0.50 \mathrm{mmol}$ ). After the solution had been stirred at $55^{\circ} \mathrm{C}$ for $4 \mathrm{~h}$, then cooled to room temperature, the white precipitate was filtered and washed successively with a mixture of ethanol and $n$-hexane (v:v $=1: 4$ ) and $n$-hexane, respectively. The product was dried under vacuum to yield the compound $\mathbf{H}_{2} \mathbf{L}^{4}$, Yield, $82.6 \%$, m.p. 359-360 K.

\section{RESULTS AND DISCUSSION}

A series of new Salamo-type bisoxime compounds $\mathbf{H}_{2} \mathbf{L}^{\mathbf{1}}$ $\mathbf{H}_{2} \mathbf{L}^{4}$ have been synthesized and the composition are confirmed by elemental analyses, IR, UV-visible and ${ }^{1} \mathrm{H}$ NMR spectra.

Physical and chemistry properties: The colour, yields, melting points and elemental analytical results of the synthesized Salamo-type bisoxime compounds $\mathbf{H}_{2} \mathbf{L}^{1}-\mathbf{H}_{2} \mathbf{L}^{4}$ are presented in Table-1.

Their compositions agree with the suggsted molecular formula. Compounds $\mathbf{H}_{2} \mathbf{L}^{1}-\mathbf{H}_{2} \mathbf{L}^{4}$ are either white or light yellow microcrystalline solid. All the compounds are stable in air and soluble in acetone, methanol, ethanol, chloroform, dichloromethane, tetrahydrofuran, ethyl acetate, DMF and DMSO, insoluble in water, ether, acetonitrile and $n$-hexane.

IR spectra: The key IR spectral bands for Salamo-type bisoxime compounds $\mathbf{H}_{2} \mathbf{L}^{1}-\mathbf{H}_{2} \mathbf{L}^{4}$ are given in Table-2.

\begin{tabular}{cccccc}
\multicolumn{7}{c}{ TABLE-2 } \\
\multicolumn{7}{c}{ KEY IR SPECTRAL BANDS $\left(\mathrm{cm}^{-1}\right)$ FOR SALAMO- } \\
TYPE BISOXIME COMPOUNDS $\mathbf{H}_{\mathbf{2}} \mathbf{L}^{1}-\mathbf{H}_{\mathbf{2}} \mathbf{L}^{4}$ \\
\hline Comp. & $v(\mathrm{O}-\mathrm{H})$ & $v\left(\mathrm{CH}_{2}\right)$ & $v(\mathrm{C}=\mathrm{N})$ & $v(\mathrm{C}=\mathrm{C})$ & $v(\mathrm{Ar}-\mathrm{O})$ \\
\hline $\mathbf{H}_{\mathbf{2}} \mathbf{L}^{1}$ & 3443 & 2942,2887 & 1606 & $1586,1473,1429$ & 1255 \\
$\mathbf{H}_{2} \mathbf{L}^{2}$ & 3438 & 2936,2885 & 1605 & $1582,1474,1427$ & 1259 \\
$\mathbf{H}_{2} \mathbf{L}^{3}$ & 3441 & 2941,2868 & 1607 & $1596,1475,1425$ & 1263 \\
$\mathbf{H}_{2} \mathbf{L}^{4}$ & 3433 & 2947,2885 & 1605 & $1593,1474,1428$ & 1259 \\
\hline
\end{tabular}

In the IR spectra of Salamo-type bisoxime compounds $\mathbf{H}_{2} \mathbf{L}^{1}-\mathbf{H}_{2} \mathbf{L}^{\mathbf{4}}$, the O-H stretching band of Salamo-type bisoxime compounds $\mathbf{H}_{2} \mathbf{L}^{\mathbf{1}}-\mathbf{H}_{2} \mathbf{L}^{4}$ is expected in the $3800-3300 \mathrm{~cm}^{-1}$ region. However, this frequency is generally displaced to about $3433 \mathrm{~cm}^{-1}$ due to the internal hydrogen bond $\mathrm{OH} \cdots \mathrm{N}=\mathrm{C}^{14}$. Thus, each unit of the polymeric ligands behaves as a dibasic tetradentate ONNO donor. As the hydrogen bond becomes stronger, the band width increases and this band sometimes is not detected. Electron-donating groups on the phenolic ring increase the electron density on the hydroxyl oxygen making the $\mathrm{H}-\mathrm{O}$ bond stronger, the absorption usually appears as a broad band in the FT-IR spectrum. Meanwhile, the characteristic $\mathrm{C}=\mathrm{N}$ stretching bands of Salamo-type bisoxime compounds $\mathbf{H}_{2} \mathbf{L}^{1}-\mathbf{H}_{2} \mathbf{L}^{4}$ appear at $1608-1605 \mathrm{~cm}^{-1}$, respectively, indicating that 3methoxy-2-hydroxybenzaldehyde has been condensated with 1,3-bis(aminooxy)propane, 1,4-bis(aminooxy)butane, 1,5bis(aminooxy)penpane and 1,6-bis(aminooxy)hexane, respectively and formed new Salamo-type bisoxime ${ }^{13,14}$ compounds $\mathbf{H}_{2} \mathbf{L}^{1}-\mathbf{H}_{2} \mathbf{L}^{4}$. In addition, the Ar-O stretching bands occur at $1263-1255 \mathrm{~cm}^{-1}$ as reported for similar bisoxime compounds ${ }^{13}$.

TABLE-1

COLOUR, YIELDS, MELTING POINTS AND ANALYTICAL DATA OF SALAMO-TYPE BISOXIME COMPOUNDS $\mathbf{H}_{2} \mathbf{L}^{1}-\mathbf{H}_{2} \mathbf{L}^{4}$

\begin{tabular}{cccccccc}
\hline \multirow{2}{*}{ Compounds } & \multirow{2}{*}{ Colour } & \multirow{2}{*}{ m.p. (K) } & \multirow{2}{*}{ Yield (\%) } & \multirow{2}{*}{ m.f. (m.w.) } & \multicolumn{2}{c}{ Elemental analysis (\%): Found (Calcd.) } \\
\cline { 6 - 8 } & & & & $\mathrm{C}$ & \multicolumn{2}{c}{$\mathrm{H}$} & $\mathrm{N}$ \\
\hline $\mathbf{H}_{2} \mathbf{L}^{\mathbf{1}}$ & White & $437 \sim 438$ & 87.7 & $\mathrm{C}_{19} \mathrm{H}_{22} \mathrm{~N}_{2} \mathrm{O}_{6}(374.3)$ & $60.44(60.95)$ & $6.07(5.92)$ & $7.12(7.48)$ \\
$\mathbf{H}_{2} \mathbf{L}^{2}$ & White & $387 \sim 388$ & 68.8 & $\mathrm{C}_{20} \mathrm{H}_{24} \mathrm{~N}_{2} \mathrm{O}_{6}(388.4)$ & $61.74(61.84)$ & $6.53(6.23)$ & $7.16(7.21)$ \\
$\mathbf{H}_{2} \mathbf{L}^{3}$ & White & $372 \sim 373$ & 63.2 & $\mathrm{C}_{21} \mathrm{H}_{26} \mathrm{~N}_{2} \mathrm{O}_{6}(402.4)$ & $63.87(63.99)$ & $7.46(7.52)$ & $6.48(6.42)$ \\
$\mathbf{H}_{2} \mathbf{L}^{4}$ & White & $359 \sim 362$ & 82.6 & $\mathrm{C}_{22} \mathrm{H}_{28} \mathrm{~N}_{2} \mathrm{O}_{6}(416.5)$ & $64.55(64.56)$ & $7.67(7.65)$ & $6.27(6.26)$ \\
\hline
\end{tabular}


UV-visible spectra: The UV-visible absorption spectra of Salamo-type bisoxime compounds $\mathbf{H}_{2} \mathbf{L}^{1}-\mathbf{H}_{2} \mathbf{L}^{4}$ (Table-3) in diluted dichloromethane solution show that the spectra of Salamo-type bisoxime compounds $\mathbf{H}_{2} \mathbf{L}^{1}-\mathbf{H}_{2} \mathbf{L}^{4}$ are similar to each other. Salamo-type bisoxime compounds $\mathbf{H}_{2} \mathbf{L}^{1}-\mathbf{H}_{2} \mathbf{L}^{4}$ exhibit two intense peaks at around 273 and $318 \mathrm{~nm}$. The former absorption peaks at about $273 \mathrm{~nm}$ can be assigned to the $\pi-\pi^{*}$ transition of the benzene rings, while the latter absorption peaks at about $318 \mathrm{~nm}$ can be attributed to the intraligand $\pi-\pi^{*}$ transition of the $\mathrm{C}=\mathrm{N}$ bonds ${ }^{15}$. It is of note that there was no absorption around $400 \mathrm{~nm}$, which are seen in the corresponding Salen derivatives. The absorption is ascribed to the quinoid form of $\mathrm{H}_{2}$ salen $^{16}$.

\begin{tabular}{cccc}
\multicolumn{4}{c}{ TABLE-3 } \\
\multicolumn{4}{c}{ UV-VISIBLE SPECTRAL DATA FOR THE } \\
\multicolumn{3}{c}{ SALAMO-TYPE BISOXIME COMPOUNDS $\mathbf{H}_{\mathbf{2}} \mathbf{L}^{1}-\mathbf{H}_{\mathbf{2}} \mathbf{L}^{\mathbf{4}}$} \\
\hline \multirow{2}{*}{ Comp. } & \multirow{2}{*}{$\left(\times 10^{-5} \mathrm{~mol} \mathrm{~L}^{-1}\right)$} & First band & Second band \\
\cline { 3 - 4 } & & $\lambda_{\max 1}(\mathrm{~nm})$ & $\lambda_{\max 2}(\mathrm{~nm})$ \\
\hline $\mathbf{H}_{2} \mathbf{L}^{\mathbf{1}}$ & 5.00 & 273 & 318 \\
$\mathbf{H}_{2} \mathbf{L}^{2}$ & 5.00 & 275 & 318 \\
$\mathbf{H}_{2} \mathbf{L}^{3}$ & 5.00 & 279 & 322 \\
$\mathbf{H}_{2} \mathbf{L}^{4}$ & 5.00 & 282 & 325 \\
\hline
\end{tabular}

${ }^{1} \mathbf{H}$ NMR spectra: The ${ }^{1} \mathrm{H}$ NMR spectra of the title compounds $\mathbf{H}_{2} \mathbf{L}^{1}-\mathbf{H}_{2} \mathbf{L}^{4}$ in DMSO- $d_{6}$ are shown in Table-4. The ${ }^{1} \mathrm{H}$ NMR spectra showed a singlet at about 8.22-8.28 ppm indicating the existence of oxime bonds ${ }^{16}$.

\begin{tabular}{|c|c|}
\hline \multicolumn{2}{|c|}{$\begin{array}{c}\text { TABLE-4 } \\
{ }^{1} \mathrm{H} \text { NMR DATA FOR SALAMO-TYPE BISOXIMES } \mathbf{H}_{2} \mathbf{L}^{1}-\mathbf{H}_{2} \mathbf{L}^{4}\end{array}$} \\
\hline Comp. & ${ }^{1} \mathrm{H}$ NMR $\left(400 \mathrm{MHz}\right.$, DMSO- $\left.d_{6}, \delta / \mathrm{ppm}\right)$ \\
\hline $\mathbf{H}_{2} \mathbf{L}^{1}$ & $\begin{array}{l}2.43-2.54\left(\mathrm{~m}, 2 \mathrm{H}, \mathrm{CH}_{2}\right), 3.89\left(\mathrm{~s}, 6 \mathrm{H}, \mathrm{CH}_{3}\right), 4.47(\mathrm{~s}, 4 \mathrm{H} \\
\left.\mathrm{CH}_{2}-\mathrm{O}\right), 6.80(\mathrm{dd}, J=7.9,2.0 \mathrm{~Hz}, 2 \mathrm{H}, \mathrm{PhH}), 6.85(\mathrm{t}, J= \\
7.7 \mathrm{~Hz}, 2 \mathrm{H}, \mathrm{PhH}), 6.90(\mathrm{dd}, J=7.8,1.6 \mathrm{~Hz}, 2 \mathrm{H}, \mathrm{PhH}) \\
8.22(\mathrm{~s}, 2 \mathrm{H}, \mathrm{N}=\mathrm{CH}), 9.70(\mathrm{~s}, 2 \mathrm{H}, \mathrm{OH})\end{array}$ \\
\hline $\mathbf{H}_{2} \mathbf{L}^{2}$ & $\begin{array}{l}\left.\text { 2.44-2.54 (m, 4H, } \mathrm{CH}_{2}\right), 3.90\left(\mathrm{~s}, 6 \mathrm{H}, \mathrm{CH}_{3}\right), 4.48(\mathrm{~s}, 4 \mathrm{H} \text {, } \\
\left.\mathrm{CH}_{2}-\mathrm{O}\right), 6.81(\mathrm{dd}, J=7.6,1.6 \mathrm{~Hz}, 2 \mathrm{H}, \mathrm{PhH}), 6.86(\mathrm{t}, J= \\
7.8 \mathrm{~Hz}, 2 \mathrm{H}, \mathrm{PhH}), 6.91(\mathrm{dd}, J=7.6,2.0 \mathrm{~Hz}, 2 \mathrm{H}, \mathrm{PhH}), \\
8.26(\mathrm{~s}, 2 \mathrm{H}, \mathrm{N}=\mathrm{CH}), 9.71(\mathrm{~s}, 2 \mathrm{H}, \mathrm{OH})\end{array}$ \\
\hline $\mathbf{H}_{2} \mathbf{L}^{3}$ & $\begin{array}{l}\left.\text { 2.45-2.55(m, 6H, } \mathrm{CH}_{2}\right), 3.90\left(\mathrm{~s}, 6 \mathrm{H}, \mathrm{CH}_{3}\right), 4.47(\mathrm{~s}, 4 \mathrm{H} \text {, } \\
\left.\mathrm{CH}_{2}-\mathrm{O}\right), 6.80(\mathrm{dd}, J=7.6,1.7 \mathrm{~Hz}, 2 \mathrm{H}, \mathrm{PhH}), 6.86(\mathrm{t}, J= \\
8.2 \mathrm{~Hz}, 2 \mathrm{H}, \mathrm{PhH}) 6.92(\mathrm{dd}, J=7.7,1.7 \mathrm{~Hz}, 2 \mathrm{H}, \mathrm{PhH}), \\
8.25(\mathrm{~s}, 2 \mathrm{H}, \mathrm{N}=\mathrm{CH}), 9.72(\mathrm{~s}, 2 \mathrm{H}, \mathrm{OH})\end{array}$ \\
\hline $\mathbf{H}_{2} \mathbf{L}^{4}$ & $\begin{array}{l}2.45-2.56\left(\mathrm{~m}, 8 \mathrm{H}, \mathrm{CH}_{2}\right), 3.91\left(\mathrm{~s}, 6 \mathrm{H}, \mathrm{CH}_{3}\right), 4.50(\mathrm{~s}, 4 \mathrm{H}, \\
\left.\mathrm{CH}_{2}-\mathrm{O}\right), 6.80(\mathrm{dd}, J=7.6,1.8 \mathrm{~Hz}, 2 \mathrm{H}, \mathrm{PhH}), 6.85(\mathrm{t}, J= \\
8.0 \mathrm{~Hz}, 2 \mathrm{H}, \mathrm{PhH}), 6.90(\mathrm{dd}, J=7.6,1.8 \mathrm{~Hz}, 2 \mathrm{H}, \mathrm{PhH}), \\
8.28(\mathrm{~s}, 2 \mathrm{H}, \mathrm{N}=\mathrm{CH}), 9.76(\mathrm{~s}, 2 \mathrm{H}, \mathrm{OH})\end{array}$ \\
\hline
\end{tabular}

\section{Conclusion}

In this work, a series of methoxy-substituted Salamo-type bisoxime compounds $\mathbf{H}_{2} \mathbf{L}^{1}-\mathbf{H}_{2} \mathbf{L}^{4}$ that have two oxime bonds instead of imine bonds have been designed and synthesized by the reaction of 2 equivalents of 3-methoxy-2-hydroxybenzaldehyde with 1,3-bis(aminooxy)propane, 1,4-bis(aminooxy)butane, 1,5-bis(aminooxy)pentane and 1,6-bis(aminooxy)hexane under hot ethanolic medium, respectively. It is shown that a bisoxime moiety is much more useful to assemble supramolecular systems than a Schiff base moiety. Further investigation on the synthesis and structures of methoxysubstituted Salamo-type complexes with transition metal ions, are now in progress.

\section{ACKNOWLEDGEMENTS}

This work was supported by the Fundamental Research Funds for the Gansu Province Universities (212086) and the science and technology support funds of Lanzhou Jiaotong University (ZC2012003), which are gratefully acknowledged.

REFERENCES

1. E.N. Jacobsen, Acc. Chem. Res., 33, 421 (2000).

2. D.J. Zhou, Q. Li, C.H. Huang, G.Q. Yao, U. Shigeo, M. Masakazu, L.M. Ying, A.C. Yu and X.S. Zhao, Polyhedron, 16, 1381 (1997).

3. T.K. Ronson, H. Adams and M.D. Ward, Inorg. Chim. Acta, 358, 1943 (2005).

4. N.S. Venkataramanan, G. Kuppuraj and S. Rajagopal, Coord. Chem. Rev., 249, 1249 (2005).

5. M. Sasaki, K. Manseki, H. Horiuchi, M. Kumagai, M. Sakamoto, H. Sakiyama, Y. Nishida, M. Sakai, Y. Sadaoka, M. Ohba and H. Okawa, J. Chem. Soc., Dalton Trans., 259 (2000).

6. S.S. Sun, C.L. Stern, S.T. Nguyen and J.T. Hupp, J. Am. Chem. Soc., 126, 6314 (2004)

7. J.C.G. Bünzli and C. Piguet, Chem. Rev., 102, 1897 (2002).

8. S. Akine, T. Taniguchi and T. Nabeshima, Chem. Lett., 30, 682 (2001).

9. W.K. Dong, J.Y. Shi, J.K. Zhong, Y.Q. Tian and J.G. Duan, Chinese J. Inorg. Chem., 24, 10 (2008).

10. P.G. Lacroix, Eur. J. Inorg. Chem., 339 (2001).

11. S. Akine, W.K. Dong and T. Nabeshima, Inorg. Chem., 45, 4677 (2006).

12. S. Akine, Y. Morita, F. Utsuno and T. Nabeshima, Inorg. Chem., 48, 10670 (2009)

13. (a) W.K. Dong, J.G. Duan, Y.H. Guan, J.Y. Shi and C.Y. Zhao, Inorg. Chim. Acta, 362, 1129 (2009); (b) W.K. Dong, X.N. He, H.B. Yan, Z.W. Lv, X. Chen, C.Y. Zhao and X.L. Tang, Polyhedron, 28, 1419 (2009); (c) W.K. Dong, L. Li, C.F. Li, L. Xu and J.G. Duan, Spectrochim. Acta A, 71, 650 (2008); (d) W.K. Dong, Y.X. Sun, C.Y. Zhao, X.Y. Dong and L. Xu, Polyhedron, 29, 2087 (2010).

14. J.A. Faniran, K.S. Patel and J.C. Bailar Jr., J. Inorg. Nucl. Chem., 36, 1547 (1974)

15. T. Ghosh, B. Mondal, T. Ghosh, M. Sutradhar, G. Mukherjee and M. Drew, Inorg. Chim. Acta, 360, 1753 (2007).

16. H.E. Smith, Chem. Rev., 83, 359 (1983). 